\title{
CONDUTAS DE GESTORES RELACIONADAS AO APOIO AO ALEITAMENTO MATERNO NOS LOCAIS DE TRABALHO
}

\author{
Vanessa Martinhago Borges Fernandes ${ }^{1}$, Evanguelia Kotzias Atherino dos Santos ${ }^{2}$, Maria de Fátima Mota \\ Zampieri ${ }^{3}$,Vitória Regina Petters Gregório ${ }^{4}$,Maria de Jesus Hernandes ${ }^{5}$, Letícia Carina Ribeiro ${ }^{6}$
}

\footnotetext{
${ }^{1}$ Mestre em Enfermagem. Programa de Pós-graduação em Enfermagem (PEN) da Universidade Federal de Santa Catarina (UFSC). Florianópolis, Santa Catarina, Brasil. E-mail: vambfernandes@gmail.com

${ }^{2}$ Doutora em Enfermagem. Professora do Departamento de Enfermagem e do PEN/UFSC. Florianópolis, Santa Catarina, Brasil. E-mail: gregos@matrix.com.br

${ }^{3}$ Doutora em Enfermagem. Professora do Departamento de Enfermagem da UFSC. Florianópolis, Santa Catarina, Brasil. E-mail: fatimazampieri@gmail.com

${ }^{4}$ Doutora em Enfermagem. Professora do Departamento de Enfermagem da UFSC. Florianópolis, Santa Catarina, Brasil. E-mail: vitoriarpg@gmail.com

${ }^{5}$ Doutoranda em enfermagem do PEN/UFSC. Florianópolis, Santa Catarina, Brasil. E-mail: mjhr_25@hotmail.com

${ }^{6}$ Doutora em Neurociências. Professora do Departamento de Nutrição da UFSC. Florianópolis, Santa Catarina, Brasil. E-mail: leribeiro1602@gmail.com
}

\section{RESUMO}

Objetivo: identificar as condutas de gestores relacionadas ao apoio ao aleitamento materno realizadas em empresas públicas e privadas da região da Grande Florianópolis, Santa Catarina.

Método: pesquisa qualitativa, exploratório-descritiva. A coleta de dados ocorreu em agosto de 2015, sendo utilizadas a entrevista semiestruturada e projetiva, em que participaram 20 gestores. A organização dos dados foi realizada através do software Atlas.ti e a análise, através da Análise de Conteúdo.

Resultados: o estudo evidenciou duas categorias. Na primeira categoria foram descritas as condutas positivas: importância da amamentação, disponibilização de informações, acompanhamento e realização de atividades durante o processo de maternidade, flexibilidade de função, horário e espaço para viabilizarem a amamentação, apoio à família, comunicação aberta, creche e bom tratamento à trabalhadora. A segunda categoria apresenta as condutas prejudiciais, na qual se constataram a indisponibilidade de informações especializadas e flexibilidade, visão negativa em relação à implantação das salas de apoio à amamentação, desconhecimento das legislações e da situação da trabalhadora, isenção da responsabilidade, indisponibilidade de creche, não ampliação da licença-maternidade, não adesão ao Programa Empresa Cidadã e não existência de política de apoio à amamentação.

Conclusão: lacunas substanciais no apoio à amamentação dos locais de trabalho foram identificadas através das condutas evidenciadas pelos gestores. Para que uma cultura pró-amamentação possa ser implantada, faz-se necessário que se construa uma rede de apoio nos locais de trabalho. Considera-se importante a reflexão sobre quais condutas devem ser incentivadas e quais devem ser modificadas ou ampliadas, para que haja um aperfeiçoamento do suporte à amamentação nos locais de trabalho.

DESCRITORES: Aleitamento materno. Trabalho feminino. Políticas públicas de saúde. Legislação. Organizações.

\section{MANAGER'S CONDUCT RELATED TO THE BREASTFEEDING SUPPORT AT THE WORKPLACE}

\begin{abstract}
Objective: to identify the behaviors of managers related to breastfeeding support in public and private companies in the region of Greater Florianópolis, Santa Catarina.

Method: qualitative, exploratory-descriptive research. The data collection was carried out in August 2015, using a semi-structured and projective interview, in which 20 managers participated. The data organization was carried out through the Atlas.ti software and the analysis through the Content Analysis.

Results: the study evidenced two categories. In the first category, positive behaviors were described: the importance of breastfeeding, providing information, monitoring and performing activities during the maternity process, flexibility of function, time and space to enable breastfeeding, family support, open communication, day care and good treatment to the worker. The second Category presents the harmful behaviors, which revealed the unavailability of specialized information and flexibility, a negative view regarding the implementation of breastfeeding support rooms, lack of knowledge of the legislation and the situation of the worker, exemption from liability, unavailability of day care, no extension of maternity leave, no adherence to the Citizen Company Program and no existence of a policy to support breastfeeding. Conclusion: substantial gaps in the breastfeeding support at the workplaces were identified through the behaviors shown by managers. In order for a pro-breastfeeding culture to be implemented, it is necessary to build a support network at the workplace. It is considered important to reflect on which behaviors should be encouraged and which should be modified or expanded, in order to improve the breastfeeding support at the workplace.
\end{abstract}

DESCRIPTORS: Breastfeeding. Female work. Public health policies. Legislation. Organizations. 


\title{
CONDUCTAS DE LOS GESTORES RELACIONADAS CON EL APOYO AL AMAMANTAMIENTO MATERNO EN LOS LUGARES DE TRABAJO
}

\begin{abstract}
RESUMEN
Objetivo: identificar las conductas de los gestores relacionadas con el apoyo para el amamantamiento materno realizadas en las empresas públicas y privadas de la región de la Gran Florianópolis, Santa Catarina.

Método: investigación cualitativa y exploratoria-descriptiva. La recolección de datos se realizó en Agosto del 2015 y se utilizó la entrevista semiestructurada y proyectiva, en la que participaron 20 gestores. La organización de los datos fue realizada a través del software Atlas.ti y el análisis a través del Análisis del Contenido.

Resultados: el estudio mostró dos categorías. En la primera categoría se describieron las conductas positivas: importancia del amamantamiento, disponibilidad de informaciones, acompañamiento y realización de actividades durante el proceso de maternidad, flexibilidad de la función, horario y espacio para viabilizar el amamantamiento, apoyo a la familia, comunicación abierta, guardería y el buen tratamiento de la trabajadora. La segunda categoría presenta las conductas perjudiciales y en la que se constataron la indisponibilidad de informaciones especializadas y flexibilidad, visión negativa en relación a la implementación de las salas de apoyo para el amamantamiento, desconocimiento de las legislaciones y de la situación de la trabajadora, exención de la responsabilidad, indisponibilidad de guardería, la no ampliación de la licencia por maternidad, la falta de adhesión al Programa Empresa Ciudadana y la inexistencia de una política de apoyo para el amamantamiento.

Conclusión: se identificaron fallas sustanciales en el apoyo al amamantamiento de los locales de trabajo a través de las conductas evidenciadas por los gestores. Para que una cultura pro-amamantamiento pueda ser implementada es necesario que se construya una red de apoyo en los lugares de trabajo. Se considera importante la reflexión sobre qué conductas deben ser incentivadas y cuáles de ellas deben ser modificadas o ampliadas para que haya un perfeccionamiento del soporte al amamantamiento en los lugares de trabajo.
\end{abstract}

DESCRIPTORES: Amamantamiento materno. Trabajo femenino. Políticas públicas de salud. Legislación. Organizaciones.

\section{INTRODUÇÃO}

Centenas de milhões de trabalhadoras no mundo não possuem proteção legal em relação ao processo da maternidade ou a possuem inadequadamente. A amamentação representa uma preocupação significante, pois fornece em curto e longo prazo vantagens econômicas e ambientais à saúde da mulher, da criança e para a sociedade como um todo. ${ }^{1}$

As evidências científicas pertinentes às recomendações para a amamentação evoluíram de forma intensificada nas últimas três décadas. ${ }^{2}$ Estimou-se em 2015 que a expansão da prática da amamentação em 75 países poderia prevenir 823.000 mortes de crianças e 20.000 mortes de mulheres a cada ano. O que corresponderia a $13,8 \%$ das mortes em crianças menores de dois anos de idade. Todavia, muitas vezes são subestimadas suas consequências. ${ }^{2}$

A entrada da mulher no mercado de trabalho está estritamente relacionada com a história da queda do aleitamento materno em nível mundial. ${ }^{3}$ Por isso, faz-se necessário um olhar mais atento à relação trabalhadora versus trabalho. As mulheres podem-se sentir satisfeitas no trabalho, mas apresentam dificuldades de sobrecarga no mesmo, dificuldades no desempenho profissional e falta de apoio dos colegas. ${ }^{4}$ Para aliar o aleitamento materno ao trabalho as empresas fornecem alguns tipos de apoio, porém os suportes são limitados. ${ }^{5}$

Trata-se de um desafio para as mães trabalhadoras sustentarem a prática da amamentação se seus gestores, chefias imediatas ou de maior hierarquia, não forem favoráveis. ${ }^{6}$ Pois, quando importantes intervenções de apoio, promoção e proteção ao aleitamento materno são oferecidas adequadamente, as respostas podem melhorar rapidamente, desde que sejam implementadas concomitantes e por vários canais. Porém, os fatores determinantes para a amamentação necessitam de suporte desde legislações, até políticas e atitudes sociais. ${ }^{1}$

A política de incentivo ao aleitamento materno no Brasil foi constituída de gestão em gestão ao longo dos últimos 80 anos. Atualmente, a Coordenação Geral de Saúde da Criança e aleitamento materno do Ministério da Saúde é o setor responsável por propor e coordenar as políticas governamentais de atenção à saúde da criança brasileira de zero a nove anos de idade. Dentre as linhas de cuidado prioritárias e principais ações está a promoção, proteção e apoio à amamentação. Concentrando seus esforços na construção de uma Política Nacional de Atenção Integral à Saúde da Criança, tal política foi reformulada e publicada em 2015 . $^{7}$

O progresso da amamentação no Brasil se dá através das ações de incentivo ao aleitamento materno, que devem ser coordenadas e realizadas em sintonia, representado pelos indicadores de políticas públicas e programas de saúde, o que tem sido bem sucedida mesmo considerando a diversidade de todo país. Em relação aos indicadores de práticas alimentares evidenciam que o país está muito aquém do que se preconiza. Entretanto, vê-se que a tendência de dados no país é crescente. ${ }^{8}$

O Brasil é exemplo na implementação simultânea de políticas e programas para a promoção, 
a proteção e o apoio ao aleitamento materno. O investimento do governo e a participação ativa da sociedade sustentam os avanços no país. ${ }^{9}$ Todavia, persistem obstáculos dentro das empresas que ainda permitem que o desmame seja precoce. ${ }^{10}$

O apoio durante a amamentação por direitos da maternidade e do trabalho para serem capazes de exercer suas atividades e continuarem amamentando não é adequado. Os padrões e determinantes da amamentação variam em diferentes contextos. A amamentação é geralmente considerada como uma decisão individual e seu sucesso tem a mulher como única responsável, ignorando o papel da sociedade para apoio e proteção. ${ }^{1}$ Dessa forma, não há perspectiva de conduta ou de conhecimento por parte dos gestores nos locais de trabalho.

O ambiente de trabalho tem correlação significativa com a relação familiar. ${ }^{4}$ Com apoio dos gestores, as trabalhadoras tendem a manter a amamentação por mais tempo. ${ }^{11}$ Em vista disso, emergiu o seguinte questionamento do estudo: Quais as condutas relacionadas ao apoio ao aleitamento materno estão sendo realizadas pelos gestores de empresas da Grande Florianópolis, Santa Catarina?

Para aprimorar o apoio à mulher que deseja aliar amamentação e trabalho e estimular a criação de uma cultura de apoio ao aleitamento materno de forma mais completa nas empresas, estabelecendo quais condutas dos gestores devem ser incentivadas e quais devem ser modificadas, definiu-se para esse estudo o objetivo de: identificar as condutas de gestores relacionadas ao apoio ao aleitamento materno realizadas em empresas públicas e privadas da região da Grande Florianópolis, Santa Catarina.

\section{MÉTODO}

Trata-se de uma pesquisa de natureza qualitativa, do tipo exploratório-descritiva, realizada na região da Grande Florianópolis, Santa Catarina, Brasil, composta por 20 empresas, sendo 10 públicas e 10 privadas. Elegeu-se como participantes 20 gestores, um de cada empresa, que apresentavam maior poder de decisão sobre a implementação de ações dentro das mesmas. O tamanho da amostra se deu por saturação teórica, sendo intencional o número igualitário dos dois tipos de empresas. Dentre os critérios de inclusão foram considerados: empresas localizadas na região da Grande Florianópolis, região dotada de número expressivo de empresas que possibilita a abordagem deste tema; e terem mais que 30 mulheres em idade fértil, este número estabelece que as empresas cumpram algumas exigências legais, tal como provimento de creches para as crianças que são amamentadas. ${ }^{12}$ Em relação aos critérios de exclusão, foi considerado: empresas que já tivessem sala de apoio à amamentação em suas instalações, pois caracterizam empresas com maior suporte e mais sensibilizadas do que as outras empresas em relação à amamentação.

Para a coleta de dados foram utilizados dois tipos de técnicas: a entrevista semiestruturada e a entrevista projetiva. ${ }^{13}$ No primeiro tipo de entrevista, fez-se uso de um roteiro relativo ao perfil do gestor, de sua empresa, seus conhecimentos e experiências em relação ao aleitamento materno. No segundo, aplicou-se um roteiro para captar a percepção dos gestores sobre espaços para amamentação dentro das empresas e suas opiniões em relação à possível implantação, após a demonstração do vídeo sobre salas de apoio à amamentação, espaços específicos para ordenha do leite materno. ${ }^{14}$ As entrevistas foram gravadas e transcritas.

A análise dos dados se desenvolveu através da técnica de Análise de Conteúdo do tipo categorial, proposta por Laurence Bardin. ${ }^{15} \mathrm{O}$ conteúdo de cada entrevista foi desmembrado em unidades chamadas codificações, que conforme similaridade de ideias foram reagrupadas em diferentes categorias, e as subcategorias, também conforme afinidades, agrupadas dentro de cada categoria. Para contribuir com a organização das informações obtidas na coleta de dados foi utilizado o software Atlas.ti, ferramenta que auxiliou no gerenciamento dos dados da pesquisa, facilitando a organização da grande quantidade de dados que as entrevistas geraram, respeitando a técnica proposta por Bardin. ${ }^{16}$

Esta pesquisa respeitou a Resolução n.466 do Conselho Nacional de Saúde e o projeto aprovado pelo Comitê de Ética em Pesquisa com Seres Humanos da Universidade Federal de Santa Catarina (UFSC) sob CAAE n 44950615500000121. Além disso, foram utilizados o Termo de Autorização do local para estudo, o Termo de Consentimento Livre e Esclarecido (TCLE), na sequência, a aprovação das transcrições pelos participantes.

\section{RESULTADOS}

O perfil dos gestores apresentou-se $75 \%$ masculino, entre 30 e 61 anos de idade, 90\% pós-graduados, $70 \%$ casados e $80 \%$ com filhos. Dos cargos ocupados, $35 \%$ eram diretores gerais, $35 \%$ diretoria e $30 \%$ gerentes. As empresas eram $50 \%$ públicas e $50 \%$ privadas, $80 \%$ possuíam filiais. Diversificaram entre os setores da segurança pública, judiciário, saúde, 
educação, indústria de eletrônica, metalúrgica, telecomunicações, comércio e cooperativa.

As condutas relacionadas ao aleitamento materno e realizadas nas empresas públicas e privadas, segundo Bardin, foram agrupadas em dois diferentes tipos conforme afinidades, resultando em duas categorias. A primeira categoria sendo condutas positivas e a segunda, condutas prejudiciais, relacionadas ao apoio do aleitamento materno nos locais de trabalho. Detectaram-se 118 codificações dentre os dados referentes às condutas adotadas pelos gestores entrevistados. Do total, $44,1 \%$ foram agrupadas na primeira categoria e $55,9 \%$ na segunda categoria. O número de codificações com relação às condutas positivas foi de 53 e a frequência com que estas temáticas foram citadas pelos gestores entrevistados foi de 131; já os listados às condutas prejudiciais totalizaram 66 codificações, as quais foram 341 vezes citadas pelos participantes.

\section{Categoria 1: Condutas positivas relacionadas ao apoio do aleitamento materno nos locais de trabalho}

As condutas positivas adotadas pelos gestores estão apresentadas conforme quadro 1 a seguir, onde cada conduta se refere a um agrupamento de codes que conferiram afinidades entre si e a frequência com que foram citadas.

Quadro 1 - Condutas positivas relacionadas ao apoio ao aleitamento materno adotadas pelas empresas.

\begin{tabular}{|l|c|c|}
\hline \multicolumn{1}{|c|}{ Condutas positivas relacionadas aleitamento materno } & $\begin{array}{c}\text { Codificações } \\
\text { agrupadas }\end{array}$ & Frequência \\
\hline $\begin{array}{l}\text { Reconhecimento da importância do aleitamento materno para a } \\
\text { empresa }\end{array}$ & 11 & 25 \\
\hline $\begin{array}{l}\text { Disponibilização de informações durante o processo de maternidade } \\
\text { (pré, parto e pós-parto) }\end{array}$ & 08 & 09 \\
\hline Acompanhamento do processo de maternidade & 01 & 05 \\
\hline $\begin{array}{l}\text { Realização de atividades de promoção, prevenção e apoio ao } \\
\text { aleitamento materno no pré-natal e puerpério }\end{array}$ & 04 & 10 \\
\hline Flexibilidade de função & 01 & 01 \\
\hline Flexibilidade de espaço & 02 & 22 \\
\hline Flexibilidade de horário & 04 & 07 \\
\hline Fornecimento de jornada de trabalho parcial & 03 & 18 \\
\hline Fornecimento de tempo máximo de licença-maternidade & 02 & 03 \\
\hline Provimento de apoio à família da trabalhadora & 02 & 02 \\
\hline Disponibilização de creche & 10 & 12 \\
\hline Realização de bom tratamento à trabalhadora & 02 & 02 \\
\hline Promoção de comunicação aberta & & 02 \\
\hline
\end{tabular}

O reconhecimento dos gestores sobre a importância da trabalhadora manter o aleitamento materno foi denotado ao responderem a pergunta sobre os benefícios deste aleitamento materno para a empresa. Eles percebem que a mulher produz mais do que antes, ou seja, demonstra um melhor desempenho, apresenta-se mais satisfeita, tem menos problemas em casa e a empresa registra menor frequência de afastamentos. E que é intangível medir esses benefícios. Já outros gestores relataram que o benefício que percebem é indireto. [...] Eu acho que a empresa tem benefício, seja em órgão público ou na iniciativa privada. A pessoa que se dispõe a trabalhar, ela tem que estar motivada para trabalhar (G9).

Algumas empresas disponibilizam informações durante o processo de maternidade quando solicitadas pelas trabalhadoras: através de seus trabalhadores, no caso daquelas que constituem profissionais da saúde, ou professores da área da 
saúde, ou equipe de saúde, saúde do trabalhador ou de enfermagem. Alguns gestores apesar de não serem da área da saúde mencionaram buscar o conhecimento ou utilizar o conhecimento adquirido pela experiência pessoal como pais para atender às demandas das mães trabalhadoras, sendo que $80 \%$ dos gestores possuíam filhos e todos os filhos haviam sido amamentados. Outros que possuem formação na área da saúde se consideraram aptos a orientar, sendo que $30 \%$ dos gestores eram formados na área da saúde, dentre eles, enfermeiros e médicos. Mas, a maioria se referia ao setor de recursos humanos, no qual as mulheres buscam prioritariamente informações para sanarem suas dúvidas. [...] A gente como gestor dá o apoio, mas quem passa a informação técnica é o pessoal da área (G12).

O acompanhamento durante o pré-parto e puerpério ocorria nas empresas que possuíam profissionais da área da saúde, ou seja, 35\% delas tinham membros da equipe de saúde capacitados para atender à mãe trabalhadora, tais como: médicos, enfermeiros, técnicos de enfermagem, odontólogos, psicólogos, nutricionistas e outros. [...] A gente toma um cuidado muito grande com isso de não colocar em locais onde faça esforço físico e de ter um acompanhamento com "feedback" (G8).

Algumas empresas realizam atividades de promoção, prevenção e apoio ao AM durante o pré-natal: $20 \%$ das empresas desenvolvem grupos de gestantes para suas trabalhadoras, com orientações de pré-parto, parto e puerpério. Somente uma das empresas deste estudo relatou proporcionar atividade no período de puerpério, após o retorno da trabalhadora da licença-maternidade, mas que esse acolhimento não é específico ao processo de maternidade. [...] Criamos um programa com o intuito social. Ele é destinado às futuras mães e acontece a cada quatro meses em todas as unidades (G7).

A pesquisa evidencia que a maior flexibilidade dos gestores foi em relação àmudança de função. Os gestores entendem que apesar de a gravidez não significar doença ela predispõe uma limitação de algumas atividades. Portanto, 30\% dos gestores referiram que eram cuidadosos, remanejando aquelas que exerciam cargos que exigiam força física. [...] $O$ cantinho da alegria, nós estávamos passando as grávidas para atuarem ali. Já que a maior parte do tempo era pra ficarem sentadas (G11).

Dos gestores, $75 \%$ citaram flexibilidade de horário nas empresas, alguns se referiram à flexibilidade como o direito da pausa para amamentar das trabalhadoras que possuem licença-maternidade de 120 dias, outros gestores referiram uma flexibilidade informal para aquelas trabalhadoras que não possuem o direito em lei de pausa para amamentar. A pausa para amamentar muitas vezes não é utilizada dentro da empresa. Outra flexibilização acontece no retorno da licença-maternidade, quando algumas trabalhadoras solicitam redução de carga horária proporcional à redução salarial, além de empresas que trabalham com sistema de banco de horas, proporcionando à mãe fazer seu próprio horário. Das empresas, 35\% proporcionam jornada de trabalho parcial para suas trabalhadoras, sendo uma carga horária de 25 a 36 horas por semana. [...] Não interessa na minha instituição, por exemplo, um funcionário que seja rigorosamente um relógio, mas que não é produtivo (G9).

A flexibilidade de espaço consistiu em fornecer um local confortável dentro da empresa em que fosse possível para a trabalhadora amamentar ou extrair o leite materno, mas este não se configurou num espaço específico e adequado. Das empresas entrevistadas, $100 \%$ não possuíam salas específicas, mas $50 \%$ delas, variando entre empresas públicas e privadas, disponibilizavam uma sala caso a mulher solicitasse. [...] Se a gente fosse rigoroso com isso, considerando que a gente tem mais de $80 \%$ do quadro feminino, a gente teria um problema muito sério (G8).

O tempo máximo de licença-maternidade significou proporcionar o tempo desta somado às férias e à licença prêmio, no caso de algumas servidoras públicas. Alguns deles, mais especificamente das instituições públicas, referem que algumas mulheres conseguem permanecer até aproximadamente um ano em casa amamentando.[...] a gente já consegue dar mais um mês de férias, para ficar mais um tempo. Elas já trabalham em cima disso, pra depois ficar mais um mês com a criança (G4).

Somente uma das empresas disponibiliza creche para os filhos das trabalhadoras, pois a empresa se configura numa escola de nível fundamental e médio. [...] Elas optam pelo desligamento... E aí a gente tem todo aquele transtorno de ter que recrutar, ter que selecionar, ter que treinar, ter que socializar (G14).

Os gestores referiram realizarem um bom tratamento às suas trabalhadoras em relação ao bem-estar, atendendo às suas necessidades e fazendo o que elas gostam. Há uma preocupação maior nas empresas nas quais as mulheres estão em maioria, mas não uma diferenciação. Também há uma cultura de preservação das pessoas, em que utilizam o bom senso nas decisões. E proporcionam clima de acolhimento, como quando as mulheres trazem os bebês para mostrarem para os colegas no local de trabalho.[...] Se ela se sente acolhida, se isso é um fator 
que conta, indiretamente é bom pra empresa que está procurando o melhor para o colaborador (G18).

Um dos gestores citou a promoção da comunicação aberta para que os problemas sejam resolvidos da melhor forma, sugerindo que a relação entre funcionário e o gestor tenha de ser franca. [...] $A$ gente tenta sempre amenizar, tenta resolver, da melhor forma pra mãe e pra criança (G4).

Alguns gestores apoiam que as mulheres constituam família e criam eventos para que os familiares venham até a empresa e conheçam o ambiente de trabalho da mãe. [...] Então, filho pra nós aqui não atrapalha (G20).

\section{Condutas prejudiciais relacionadas ao apoio} do aleitamento materno nos locais de trabalho

As condutas prejudiciais relacionadas ao apoio do aleitamento materno adotadas pelas empresas participantes estão apresentadas no quadro 2, onde cada conduta se refere a um agrupamento de codes que conferiram afinidades entre si e a frequência com que foram citadas.

\section{Quadro 2 - Condutas prejudiciais relacionadas ao apoio ao aleitamento materno adotadas pelas empresas.}

\begin{tabular}{|l|c|c|}
\hline Condutas prejudiciais relacionadas ao apoio ao aleitamento materno & $\begin{array}{c}\text { Codificações } \\
\text { agrupadas }\end{array}$ & Frequência \\
\hline $\begin{array}{l}\text { Indisponibilidade de informações durante o processo de maternidade } \\
\text { à trabalhadora }\end{array}$ & 10 & 48 \\
\hline $\begin{array}{l}\text { Visão negativa sobre a implantação de sala de apoio à amamentação } \\
\text { na empresa }\end{array}$ & 20 & 38 \\
\hline $\begin{array}{l}\text { Indisponibilidade de sala para amamentação ou extração do leite } \\
\text { materno }\end{array}$ & 03 & 19 \\
\hline $\begin{array}{l}\text { Indisponibilidade de creche para os filhos das trabalhadoras que } \\
\text { amamentam }\end{array}$ & 02 & 09 \\
\hline Fornecimento de licença-maternidade de no máximo 120 dias & 02 & 20 \\
\hline Não adesão ao ProgramaEmpresa Cidadã & 01 & 12 \\
\hline Inflexibilidade de horários & 02 & 12 \\
\hline $\begin{array}{l}\text { Determinação de jornada de trabalho integral às trabalhadoras que } \\
\text { amamentam }\end{array}$ & 03 & 40 \\
\hline Desconhecimentodas legislações relativas ao aleitamento materno & 05 & 45 \\
\hline Desconhecimento da situação da trabalhadora que amamenta & 10 & 23 \\
\hline Não existência de política escrita de aleitamento materno na empresa & 01 & 05 \\
\hline $\begin{array}{l}\text { Apresentação de justificativaspara falta de apoio ao aleitamento } \\
\text { materno de sua empresa }\end{array}$ & 17 \\
\hline
\end{tabular}

Dos gestores, $80 \%$ referiram que não disponibilizavam informações quando as mulheres possuem alguma dúvida sobre gestação, parto e puerpério, e os recursos humanos costumam proporcionar informações somente técnicas. Ou seja, $15 \%$ dessas empresas possuem profissionais da saúde que não realizam orientações específicas às trabalhadoras. Além disso, não desenvolvem atividades específicas, como grupo de gestantes e nem acolhimento da trabalhadora após o retorno da licença-maternidade. [...] Sobre amamentação e outros assuntos não é feita orientação, o profissional vai buscar na área de saúde fora [...] (G2). [...] Eu concebo que isso cabe aos recursos humanos, mas os recursos humanos não acho preparado para isso (G5).

A percepção dos gestores quanto à implantação das salas de apoio à amamentação indicam que estes vislumbram mais dificuldades do que facilidades, ou seja, há uma visão mais negativa do que positiva relativa ao espaço específico e adequado para a amamentação. Essa percepção está associada a fatores como o de custo financeiro, espaço físico, tempo de pausa para amamentar, de licença-maternidade e de jornada de trabalho, funcionalidade 
da sala de apoio à amamentação, conscientização do apoio à trabalhadora que amamenta, visão do gestor, responsabilidades do governo e das próprias empresas, e o da existência de política escrita de aleitamento materno na empresa. Nenhuma das empresas possuía sala de apoio à amamentação, somente uma delas apresentava estrutura semelhante, sendo o Banco de Leite Humano. [...] A fragilidade está na concepção da própria sociedade como um todo, no sentido de incorporar isso (G5).

Além de não disponibilizarem salas para amamentação/ordenha do leite materno, 95\% não possuíam creche para os filhos das trabalhadoras que amamentam. Somente $35 \%$ proporcionavam auxílio-creche. O tempo máximo de licença-maternidade de 120 dias foi fornecido por $50 \%$ dos gestores, a saber, todas as empresas privadas, sendo que nenhum dos gestores aderiu ao Programa Empresa Cidadã. [...] Sim, auxílio creche, precisa apresentar o recibo. Também para cuidador, por exemplo, babá (G1).

Dos gestores, $10 \%$ referiram inflexibilidade de horário. Além de indicarem que não houve solicitações de salas de apoio à amamentação, 50\% dos gestores, ao lhes perguntar sobre o fornecimento de flexibilidade de horário ou pausa para amamentar, em relação àquelas que não possuem esse direito porque já desfrutam licença-maternidade de 180 dias, relataram que nenhuma delas fez essa solicitação. Das empresas, $60 \%$ possuem trabalhadoras que cumprem jornada de trabalho integral, de 40 a 44 horas por semana. [...] não, ninguém solicitou [...] (G3). [...] Nós não temos nem estrutura física e nem efetivo o suficiente que a gente permita liberar essa funcionária (G19).

Há desconhecimento do gestor em relação às legislações sobre aleitamento materno. Todos os gestores desconheciam a nota técnica sobre as salas de apoio à amamentação, alguns desconheciam o Programa Empresa Cidadã, outrosalegaram que cumpriam o que a lei obriga.[...] saber que existe uma nota técnica sobre isso não, nunca tive acesso (G16).

Sobre o desconhecimento do gestor em relação à situação da trabalhadora que amamenta, alguns referiram que não sabem se após o retorno da licença-maternidade elas ainda continuam amamentando e outros acreditam que elas retornam já em desmame. A maioria dos gestores, mesmo os mais experientes, relatou que não tivera nenhuma experiência com trabalhadoras amamentando e que elas normalmente não fazem pedidos especiais. E que a trabalhadora, às vezes, sente-se coagida para fazer pedidos, ou os pedidos nunca chegam ao diretor, porque são casos esporádicos ou porque não há demanda. [...] Porque às vezes não consegue conversar com a gente. Não sei se é por hierarquia, até por medo (G4).

Nenhum dos gestores referiu sobre a existência de uma política escrita na empresa de apoio aleitamento materno, mas $20 \%$ delas possuíam protocolos para seus clientes, pacientes ou alunas. Alguns gestores também relataram que tentaram realizar algumas ações de promoção ao aleitamento materno, mas que essas ações isoladamente não obtiveram sucesso, como o exemplo do gestor que investiu em bombas de extração de leite materno sem obter sala específica e nem orientações para uso. [...] Por enquanto não existe uma norma, existe uma política informal [...] (G17). [...] A sala deve vir junto com uma campanha, não vem por uma decisão (G13).

Dos gestores, 55\% fizeram diferenciações, na tentativa de justificar a falta de apoio ao aleitamento materno em sua empresa. Primeiro, o gestor de uma empresa pública, referindo-se às empresas de grande porte; depois o gestor de uma empresa pública que citou as empresas privadas; a seguir, a gestora mulher se justificando pela conduta do gestor homem; e por fim, o gestor de uma empresa de jornada parcial se referindo às empresas com jornada integral de trabalho. [...] E reporto que em instituições maiores, tanto públicas, quanto privadas, é essencial [...] (G16). [...] Para a privada seria mais útil [...] (G2). [...] Eu vejo que se for um gestor homem, se está no horário de trabalho, acha que só vai atrapalhar. [...] (G14). [...] Essas salas aí, elas são mais necessárias nas empresas que têm uma jornada de trabalho acima de oito horas (G10).

\section{DISCUSSÃO}

A mulher trabalhadora que amamenta é uma das ações estratégicas do eixo de aleitamento materno e alimentação complementar saudável, pertencente à Política Nacional de Atenção Integral à Saúde da Criança, no Brasil; e ancorada na promoção, proteção e apoio ao aleitamento materno, iniciando na gestação, considerando-se as vantagens da amamentação para a criança, a mãe, a família e a sociedade, bem como a importância de estabelecimento de hábitos alimentares saudáveis. ${ }^{7}$

Além das vantagens para a mãe, o filho, família e sociedade, as empresas também se beneficiam com o apoio ao aleitamento materno, através do menor absenteísmo da trabalhadora, ela passa a ter maior adesão ao emprego e a empresa conquista uma imagem mais positiva perante os funcionários e a sociedade. ${ }^{17}$ Os gestores deste estudo reconhe- 
cem que o aleitamento materno traz benefícios para empresa, percebem que, além daquilo que a literatura comprova, as mulheres tornam a possuir melhor desempenho quando conseguem conciliar a amamentação e o trabalho.

Estas mulheres sentem necessidade de serem apoiadas desde o pré-natal até o puerpério, tanto pela família como pelos profissionais de saúde. ${ }^{18}$ Por meio da promoção e do apoio dos gestores se pode influenciar o tempo em que a mulher amamenta e contribuir para melhor saúde da mãe e de seu bebê. ${ }^{19}$ Alguns gestores deste estudo utilizaram sua experiência pessoal para orientar quando as mulheres precisavam sanar alguma dúvida específica do processo de maternidade, a minoria das empresas disponibilizava informações através de profissionais capacitados. A maioria delas procura o setor dos recursos humanos para sanar suas dúvidas, mas somente obtém informações técnicas sobre normas e legislações.

Ademais, o acompanhamento no pré-parto e puerpério ocorria somente nas empresas que possuíam profissionais da área da saúde. A maioria das mulheres, segundo os gestores deste estudo, faziam acompanhamento externamente ao trabalho. Esse acompanhamento não deve se limitar somente ao pré-natal, é necessário que haja um acolhimento após o retorno da mulher ao trabalho. As percepções, saberes, sentimentos e experiências prévias das gestantes são fatores importantes para a promoção da saúde. A literatura traz que, durante o período pré-natal, é importante a orientação abordada em grupos de gestantes, podendo levá-las a se sentirem mais seguras para superar as possíveis adversidades do período gestacional e amamentação. ${ }^{20}$

Ações educacionais individuais ou em grupo são ferramentas importantes para realizar mudanças a respeito das percepções referentes à amamentação. ${ }^{21}$ Entretanto, neste estudo, observaram-se empresas que não disponibilizavam informações e não realizavam atividades específicas, e outras empresas que realizavam trabalhos específicos, como os grupos de gestantes e acolhimento após o retorno da licença-maternidade.

Além das atividades relacionadas ao processo de maternidade, existem também alguns tipos de flexibilidade que o gestor pode disponibilizar. A primeira delas é a flexibilidade de função. Alguns gestores deste estudo referiram haver um remanejamento das trabalhadoras quando estas estão em funções que não estão de acordo com as limitações do período gestacional, mas não que há flexibilidade de função no período da amamentação. Segundo a literatura, pelas alterações provocadas pela gestação deve haver a adequação das posições de trabalho e quanto à jornada de trabalho. ${ }^{22}$ Dados sobre a flexibilidade de função no período de aleitamento materno não foram encontrados na literatura.

Quanto à flexibilidade de horário, a maioria dos gestores do estudo refere possibilitar algum tipo de flexibilidade. Os tipos foram: pausa para amamentar, redução de carga horária, mudança de horário de trabalho conforme necessidade da trabalhadora ou mudança para jornada de trabalho parcial. Na literatura, sobre o efeito do trabalho em tempo parcial, as políticas sugerem que as trabalhadoras possam utilizar o tempo de férias, realizarem acordos com sua chefia ou combinarem horários flexíveis. ${ }^{23}$

Também, as mulheres que amamentam manifestam a insuficiência de pausas para realizar a extração do leite materno. ${ }^{24} \mathrm{Nem}$ todos os regimes trabalhistas fornecem o direito à mulher de pausa para amamentação, mas, observou-se que alguns gestores, informalmente, são flexíveis quando há pedidos de suas trabalhadoras. No Brasil, a pausa para amamentação é garantida por lei somente para o servidor em regime celetista. ${ }^{12}$ Após os seis meses, a pausa continua sendo necessária até que se cesse completamente o aleitamento materno, que pode durar até dois anos ou mais..$^{25}$

Em relação à flexibilidade de local, metade dos gestores deste estudo relatou proporcionar um espaço não específico para a trabalhadora amamentar, caso houvesse solicitação. Porém, deve-se estabelecer um ambiente apropriado para a amamentação dentro das empresas, pois espaços destinados à lactação aumentam o desejo da mulher trabalhadora de continuar amamentando. ${ }^{23-26}$

A estratégia de apoio à mulher trabalhadora que amamenta compreende em gerar nas empresas públicas e privadas uma cultura de respeito e apoio à amamentação como forma de promover a saúde da mulher trabalhadora e de seu bebê, trazendo benefícios diretos para a empresa e para o país. O objetivo é garantir a manutenção do aleitamento materno quando a mãe retorna ao trabalho e os direitos da criança à amamentação. Esta ação está baseada em três eixos: na conquista da licença maternidade de 180 dias em todo território nacional, na implantação de creches e salas de apoio à amamentação em empresas, conforme legislação. ${ }^{15}$

Relativo à sala de apoio à amamentação, os gestores apresentaram mais dificuldades do que facilidades para a implantação. Mas, independente da percepção da falta de demanda, os gestores deste estudo indicaram que esses locais devem ser 
implementados. É clara a percepção daqueles que se opõe e que defendem crenças de desvantagens para a empresa. ${ }^{27}$ Por isso, é importante sensibilizar as instituições para a importância da manutenção da amamentação e desmistificação dos prejuízos. ${ }^{11} \mathrm{E}$ para que esse benefício tenha êxito, a mãe necessita receber informação e treinamento para ordenhar, armazenar e oferecer seu leite adequadamente. ${ }^{28}$

Outro tipo de espaço que deve ser fornecido são as creches para os filhos das trabalhadoras que amamentam. No Brasil, o regime celetista obriga toda empresa que trabalhe com pelo menos de 30 mulheres, maiores de 16 anos de idade, a terem creche durante o período da amamentação, que pode ser suprido por meio de convênios. ${ }^{12}$ Encontrou-se a disponibilidade de creche somente em uma das empresas. Sendo que um dos critérios de seleção do local de pesquisa era de empresas com número maior que 30 mulheres em idade fértil, mesmo que algumas delas forneçam o auxílio-creche, observou-se que nem todas estão cumprindo o que a legislação prevê.

Os empregadores podem, inadvertidamente, violar leis de proteção à amamentação, simplesmente por não estarem cientes das legislações. ${ }^{29}$ Os gestores desta pesquisa desconheciam algumas legislações referentes à mulher trabalhadora que amamenta, além de alguns deles descumprirem algumas leis. Uma delas era sobre as salas de apoio à amamentação, onde nenhuma das empresas a possuía, mas que ainda não é obrigatória. ${ }^{17}$ Também sobre o Programa Empresa Cidadã, onde as empresas que ainda concedem o tempo de licença-maternidade de 120 dias poderiam se beneficiar através de incentivo fiscal do governo, que é facultativa. ${ }^{30}$

O cumprimento das leis trabalhistas, especificamente de proteção à amamentação, parece ser fundamental em uma sociedade como a brasileira, em que quase $25 \%$ da população economicamente ativa é constituída por mulheres com filhos menores de seis meses de idade. ${ }^{28} \mathrm{O}$ não cumprimento destas leis trabalhistas em favorecimento ao aleitamento materno pelas empresas são alguns destes obstáculos que precisam ser revistos e aprofundados em outros estudos. ${ }^{10}$

Em relação à legislação da licença-maternidade, as evidências demonstram que ela está positivamente associada à maior duração do aleitamento materno. A licença-maternidade remunerada deveria ser de cumprimento adequado para proteger a relação materno/infantil e por, pelo menos, a duração recomendada. ${ }^{25}$

Além de proporcionar o tempo de licença-maternidade, os gestores relataram oportunizar o tempo máximo de afastamento da trabalhadora para que ela possa efetivar o aleitamento materno, somando o tempo de licença ao tempo de férias disponível. No caso das servidoras privadas, o tempo médio de afastamento relatado é de 150 dias, 120 dias de licença maternidade somados aos das férias. E para as trabalhadoras públicas, que possuem licença de 180 dias, férias e em alguns casos licença-prêmio de três meses, esse tempo passa a ser de 300 dias de afastamento. As mulheres que retornam mais tarde da licença-maternidade são mais propensas a amamentar por mais tempo. ${ }^{26} \mathrm{O}$ afastamento máximo possibilita que a trabalhadora cumpra o aleitamento materno exclusivo por seis meses como o recomendado mundialmente. ${ }^{25}$

O tempo de afastamento depende de uma comunicação dos gestores com suas trabalhadoras, pois exige negociação. Os dados deste estudo revelam o desconhecimento da situação da trabalhadora pelos gestores ao relatarem que não tiveram experiências com mulheres amamentando, sendo que as empresas possuem uma rotatividade de trabalhadoras grávidas. E daqueles que não recebem nenhum pedido das mulheres relacionado à amamentação, fazendo com que tenham uma visão de que os casos são esporádicos ou que não possuem demanda suficiente para melhorarem seus apoios.

Outra forma de apoio que também fora levantado por alguns gestores condiz à família, pois reconhecem que o apoio familiar é indispensável. Na literatura este apoio é citado como fundamental, sendo uma fonte de encorajamento na construção do vínculo entre mãe e filho, e sem ele o desmame pode ocorrer mais precocemente. ${ }^{31}$

As grandes empresas podem ser capazes de fornecer benefícios mais favoráveis devido a maior quantidade de recursos e as empresas menores podem precisar de fontes externas, tais como consultores de lactação para informá-los sobre os benefícios de prestação de apoio à amamentação e assistência na elaboração de um programa de aleitamento materno adequado para seus empregados. ${ }^{5}$

Para isso, faz-se necessária a elaboração de uma política de apoio ao aleitamento materno escrita em cada local de trabalho, pois ações isoladas mesmo que bem intencionadas podem fadar ao insucesso. As mulheres são mais propensas a manter a amamentação quando elas estão conscientes de políticas favoráveis de apoio ao aleitamento maternonas suas empresas. ${ }^{32}$ Todavia, nenhum dos gestores deste estudo referiu haver algo escrito em relação à amamentação. Tal política aumenta significativamente a chance da trabalhadora continuar amamentando. 
Além disso, nem todas as mulheres retornam à empresa devido à falta de apoio no local de trabalho. ${ }^{29-30}$ E mesmo algumas mulheres que desmamaram precocemente diante de situações adversas podem compreender o significado do aleitamento materno e ter esperança de vivenciar a amamentação com sucesso em próximas experiências. ${ }^{10}$

Por fim, observou-se um lado positivo no apoio ao aleitamento materno presente em todas as empresas, que foi o tipo de tratamento prestado às mulheres pelos gestores. $\mathrm{O}$ mercado de trabalho brasileiro é um espaço relativamente masculino, onde as mulheres ainda sofrem todo tipo de discriminação, o que faz com que elas necessitem de esforço extra para equilibrar as atividades produtivas e reprodutivas. ${ }^{33}$ Assim, ao decidir apoiá-la e favorecê-la, o gestor traça uma característica a favor de uma possível mudança na cultura de apoio ao aleitamento materno no trabalho.

\section{CONCLUSÃO}

Oestudo sobre as condutas de gestores relacionadas ao apoio ao aleitamento materno nos locais de trabalho, realizado em empresas públicas e privadas da região da Grande Florianópolis, Santa Catarina, evidencia em seus resultados duas categorias: uma primeira relacionada com condutas positivas e a segunda, relacionada às condutas prejudiciais.

Em relação à primeira categoria, destacamos como condutas principais: o reconhecimento da importância do aleitamento materno para a empresa, a disponibilização de informações, acompanhamento e realização de atividades durante o todo processo de maternidade, flexibilidade de função, espaço e de horário, disponibilização de creches, apoio à família, entre outras. Na segunda categoria, os gestores apontam como principais condutas prejudiciais: a indisponibilidade de informações durante o processo de maternidade, visão negativa sobre a implantação de sala de apoio à amamentação, indisponibilidade de espaço para amamentação, indisponibilidade de creche, licença-maternidade de no máximo 120 dias, não adesão ao Programa Empresa Cidadã, inflexibilidade de horários, desconhecimento das legislações, inexistência de política escrita de aleitamento materno na empresa, entre outras. Trazendo à reflexão quais condutas devem ser incentivadas e quais devem ser modificadas, para que haja um aperfeiçoamento do suporte à amamentação nos locais de trabalho.

Portanto, recomendamos aos profissionais de saúde maiores investimentos na sensibilização dos gestores; aos pesquisadores, outros estudos para investigar outras formas de suporte e sobre o impacto destes na manutenção da amamentação; aos governantes, melhores investimentos no trabalho dos profissionais de saúde voltado para esta temática e implementação de políticas que apoiem as trabalhadoras após o retorno da licença-maternidade; e aos legisladores, elaboração de melhores normatizações sobre as condições de trabalho para as mães trabalhadoras: fornecimento de creches aos seus filhos, aumento do tempo de licença-maternidade, estabelecimento de pausas para amamentação e a obrigatoriedadeda implantação das salas de apoio à amamentação nas empresas, revendo o conceito de proteção à maternidade daquelas que escolheram conciliar vida pessoal e profissional.

\section{REFERÊNCIAS}

1. Rollins NC, Lutter CK, Bhandari N, Hajeebhoy N, Horton S, Martines JC, et al. Why invest, and what it will take to improve breastfeeding practices? Lancet Glob Health [internet]. Ahead of print Epub 30 jan 2016 [cited 2016 May 05]. Avaiable from: http:/ / www. thelancet.com/series/breastfeeding

2. Victoria CG, Barros AJD, França GVA, Bahl R, Rollins NC, Horton S, et al. Breastfeeding in the 21st century: epidemiology, mechanisms, and lifelong effect. Lancet Glob Health [internet]. Ahead of print Epub 30 jan 2016 [cited 2016 May 05]. Avaiable from: http:/ / www. thelancet.com/series/breastfeeding

3. Palmer G. The politics of breastfeeding. London (UK): Pandora Press; 1988.

4. D'Affonseca SM, Cia F, Barham EJ. Trabalhadora feliz, mãe feliz? Condições de trabalho que influenciam na vida familiar. Psicol Argum [Internet]. 2014 Jan [cited 2017 Mar 05]; 32(76):129-38. Available from: http:/ / scholar.googleusercontent.com/scholar? $\mathrm{q}=$ cache:UpkTZHs96sJ:scholar.google.com/+trabalhadora+fel iz + mae + feliz\&hl $=$ pt-BR\&as_sdt $=0,5$

5. Hojnacki SE, Bolton T, Fulmer IS, Olson BH. Development and piloting of an instrument that measures company support for breastfeeding. J Hum Lact [Internet]. 2012 Jan [cited 2014 Oct 10]; 28(1):20-27. Available from: http://www.scopus.com/inward/ record.url?eid=2-s2.0-84856092712\& partnerID $=40 \&$ md5=46fbd9a4b25ab18adef7e85098a272d7

6. Hirani SAA, Karmaliani R. Evidence based workplace interventions to promote breastfeeding practices among Pakistani working mothers. Women Birth [Internet]. 2013 Mar [cited 2014 Oct 10];26(1):106. Available from: http://dx.doi.org/10.1016/j. wombi.2011.12.005

7. Ministério da Saúde (BR), Gabinete do Ministro. Portaria n 1.130 de 05 de agosto de 2015: institui a Política Nacional de Atenção Integral à Saúde da 
Criança (PNAISC) no âmbito do Sistema Único de Saúde (SUS). Brasília (DF): MS; 2015. Available from: http://www.brasilsus.com.br/index.php/ legislacoes/gabinete-doministro/4007-portaria-n-1130-de-5-de-agosto-de-2015

8. IBFAN Brasil. Situação da estratégia global para alimentação de lactentes e crianças da primeira infância. Jundiaí: SP; 2014.

9. Ministério da Saúde (BR). Secretaria de Atenção à Saúde. Área Técnica de Saúde da Criança e Aleitamento Materno. Gestões e gestores de políticas públicas de atenção à saúde da criança: 70 anos de história. História da Saúde. Brasília (DF): MS; 2011.

10. Prado CVC, Fabbro MRC, Ferreira GI. Early weaning from breastfeeding from mothers' perspective: a dialogical approach. Texto Contexto Enferm [Internet]. 2016Jun [cited $2016 \mathrm{Jul} 12]$; 25(2):e1580015. Available from: http://dx.doi.org/10.1590/010407072016001580015.

11. Pedroso RMCJ, Galvão DMG, Castro FV. Amamentação em mulheres trabalhadoras e alunas do ensino superior público de Coimbra. Rev Psicol [Internet]. 2014 Jan [cited 2015 Sep 04]; 1(2):419-24. Available from: http:/ / dehesa.unex.es:8080/xmlui/bitstream/ handle/10662/1083/0214-9877_2013_2_1_419. pdf? sequence $=1$

12. Brasil. Decreto-lei n. 5.452, de 01 de maio de 1943. Consolidação das Leis do Trabalho (CLT). Rio de Janeiro (RJ): 1943.

13. Minayo MCS. O desafio do conhecimento: pesquisa qualitativa em saúde. São Paulo (SP): Hucitec; 2013.

14. Aranda G, Monteiro NR. Garantir a amamentação até os 6 meses de vida do bebê é um desafio da saúde pública do Brasil [Vídeo].2012 [cited $2015 \mathrm{dez}$ 14]. Available from: https://www.youtube.com/ watch?v=KrPwjDxty1k

15. Bardin L. Análise de conteúdo. São Paulo (SP): Edições 70; 2011.

16. Friese S. Atlas.ti 6 quick tour. Berlin: Atlas.ti Scientific Software Development GmbH; 2010.

17. Ministério da Saúde (BR). Agência Nacional de Vigilância Sanitária. Guia para implantação de salas de apoio à amamentação para a mulher trabalhadora. Brasília (DF): MS; 2015.

18. Lima IMSO, Leão TM, Alcântara MAR. Proteção legal à amamentação, na perspectiva da responsabilidade da família e do Estado no Brasil. Rev Dir Sanit [Internet]. 2013 Jan [cited 2015 Sep 04]; 14(3):66-90. Available from: http:/ / www.revistas.usp.br/rdisan/ article/view/75649

19. Abdulwadud OA, Snow ME. Interventions in the workplace to support breastfeeding for women in employment. Cochrane Libr [Internet]. 2012 Aug [cited 2015 Sep 08]; 10: CD006177; Available from: http:// onlinelibrary.wiley.com/doi/10.1002/14651858. CD006177.pub3/epdf
20. Frigo LF, Silva RM, Boeira GS, Manfio F. A importância dos grupos de gestantes na atenção primária: um relato de experiência. Rev Epidemiol Controle Infecc[Internet]. 2012 Ago [cited 2015 Sep 23]; 2(3):1134. Available from: http:// online.unisc.br/seer/index. php/epidemiologia/article/view/2745/2195

21. Silva CA, Davim RMB. Mulher trabalhadora e fatores que interferem na amamentação: revisão integrativa. Rev Rene [Internet]. 2012 Jan [cited 2015 Sep 04]; 13(5):1208-17. Available from: http:// www.revistarene.ufc.br/revista/index.php/revista/ article/view/1171/pdf

22. Silva CR, Santos WM, Pontes EMR, Boas VHV. Perfil das trabalhadoras gestantes de um município do interior paulista. Rev Saúde[Internet]. 2013 Jan [cited 2015 Sep 23]; 7(2):17-23. Available from: http:// www.revistas.ung.br/index.php/saude/article/ view/1469/1293

23. Abdulloeva S, Eyler AA. Policies on worksite lactation support within states and organizations. Res J Womens Health [Internet]. 2013 Apr [cited 2015 Oct 10]; 22(9):769-74. Available from: http://www.scopus. com/inward/record.url?eid=2-s2.0-84883675861\&par therID=40\&md5=52db6daef729e9784bccd7cbe437f016

24. Cooklin AR, Rowe HJ, Fisher JRW. Paid parental leave supports breastfeeding and mother-infant relationship: a prospective investigation of maternal postpartum employment. Aust N Z J Public Health [Internet]. 2012 Mar [cited 2014 Oct 10]; 36(3):249-56. Available from: http://dx.doi.org/10.1111/j.17536405.2012.00846.x

25. Organização Mundial de Saúde. Evidências científicas dos dez passos para o sucesso no aleitamento materno. Tradução de Maria Cristina. G do Monte. Brasília (DF): 2001.

26. Tsai S. Impact of a breastfeeding-friendly workplace on an employed mother's intention to continue breastfeeding after returning to work. Breastfeed Med [Internet]. 2013 Jan [cited 2014 Oct 10]; 8(2):210-6. Available from: http://www.scopus.com/inward/ record.url?eid=2-s2.0-84876156582\& partnerID $=40 \&$ md5=04af1b98cafd7839a1e1bdabf2e7e078

27. Bai YK, Wunderlich SM, Weinstock M. Employers' readiness for the mother-friendly workplace: an elicitation study. Matern Child Nutr [Internet]. 2012 Jan [cited 2014 Oct 10]; 8(4):483-91. Available from: http:/ / www.scopus.com/inward/record.url?eid=2s2.0-84865746167\&partnerID $=40 \& \mathrm{md} 5=\mathrm{a} 7 \mathrm{c} 711243 \mathrm{c} 88$ 470330ef3a23fba503e3

28. Brasileiro AA, Ambrosano GMB, Marba STM, Possobon RF. Amamentação entre filhos de mulheres trabalhadoras. Rev Saúde Públ [Internet]. 2012 Mar [cited 2014 Oct 10]; 46(4):642-8. Available from: http://www.scielosp.org/scielo.php?script=sci arttext\&amp

29. Nguyen TT, Hawkins SS. Current state of US breastfeeding laws. Matern Child Nutr [Internet]. 2013 
Dec [cited 2014 Oct 10]; 9(3):350-8. Available from: http:/ / dx.doi.org/10.1111/j.1740-8709.2011.00392.x

30. Brasil. Lei n. 11.770, de 09 de setembro de 2008. Cria o Programa Empresa Cidadã, destinado à prorrogação da licença-maternidade mediante concessão de incentivo fiscal.Programa Empresa Cidadã. Brasília (DF): MS; 2008.

31. Araújo VS, Medeiros APDS, Barros ADC, Braga LS, Trigueiro JVS, Dias MD. Early weaning: aspects of the experiences of informal workers. Rev Enferm Referência [Internet]. 2013 Jul [cited 2014 Oct 10]; 3(10):35-43. Available from: http:/ / www.scielo.mec. pt/pdf/ref/vserIIIn10/serIIIn10a05.pdf
32. Chang SM, Rowe J, Goopy S. Non-family support for breastfeeding maintenance among career women in Taiwan: a qualitative study. Int J Nurs Pract [Internet]. 2014 Jan [cited 2014 Oct 10]; 20(3):293-301. Available from: https://onlinelibrary.wiley.com/ doi/abs/10.1111/ijn.12148

33. Bruschini MCA. Trabalho da mulher: igualdade ou proteção? Cad Pesqui Fund Carlos Chagas[Internet]. 1987[cited 2015 Sep 24]; 61(1):58-67. Available from: http://publicacoes.fcc.org.br/ojs/index.php/cp/ article/view/1244/1248 